\title{
OPEN Advanced characterization of biomineralization at plaque layer and inside rice roots amended with iron- and silica-enhanced biochar
}

Guanhong Chen ${ }^{1 凶}$, Sarasadat Taherymoosavi², Soshan Cheong ${ }^{3}$, Yao Yin ${ }^{3}$, Rabeya Akter ${ }^{3}$, Christopher E. Marjo ${ }^{3}$, Anne M. Rich ${ }^{3}$, David R. G. Mitchell ${ }^{4}$, Xiaorong Fan ${ }^{5}$, Jinkiat Chew ${ }^{5}$, Genxing Pan ${ }^{5}$, Lianqing Li ${ }^{5}$, Rongjun Bian ${ }^{5}$, Joseph Horvat ${ }^{6}$, Mohanad Mohammed ${ }^{6}$, Paul Munroe ${ }^{2} \&$ Stephen Joseph ${ }^{2,6 \bowtie}$

Application of iron (Fe)- and silica (Si)-enhanced biochar compound fertilisers (BCF) stimulates rice yield by increasing plant uptake of mineral nutrients. With alterations of the nutrient status in roots, element homeostasis (e.g., Fe) in the biochar-treated rice root was related to the formation of biominerals on the plaque layer and in the cortex of roots. However, the in situ characteristics of formed biominerals at the micron and sub-micron scale remain unknown. In this study, rice seedlings (Oryza sativa L.) were grown in paddy soil treated with BCF and conventional fertilizer, respectively, for 30 days. The biochar-induced changes in nutrient accumulation in roots, and the elemental composition, distribution and speciation of the biomineral composites formed in the biochar-treated roots at the micron and sub-micron scale, were investigated by a range of techniques. Results of laser ablation inductively coupled plasma mass spectrometry (LA-ICP-MS) showed that biochar treatment significantly increased concentrations of nutrients (e.g., $\mathrm{Fe}, \mathrm{Si}$, and $\mathrm{P}$ ) inside the root. Raman mapping and vibrating sample magnetometry identified biochar particles and magnetic Fe nanoparticles associated with the roots. With $\mathrm{Fe}$ plaque formation, higher concentrations of $\mathrm{FeO}_{x}{ }^{-}$and $\mathrm{FeO}_{x} \mathrm{H}^{-}$ anions on the root surface than the interior were detected by time-of-flight secondary ionization mass spectrometry (ToF-SIMS). Analysis of data from scanning electron microscopy energy-dispersive spectroscopy (SEM-EDS), and from scanning transmission electron microscopy (STEM) coupled with EDS or energy electron loss spectroscopy (EELS), determined that Fe(III) oxide nanoparticles were accumulated in the crystalline fraction of the plaque and were co-localized with $\mathrm{Si}$ and $\mathrm{P}$ on the root surface. Iron-rich nanoparticles (Fe-Si nanocomposites with mixed oxidation states of Fe and ferritin) in the root cortex were identified by using aberration-corrected STEM and in situ EELS analysis, confirming the biomineralization and storage of $\mathrm{Fe}$ in the rice root. The findings from this study highlight that the deposition of Fe-rich nanocomposites occurs with contrasting chemical speciation in the Fe plaque and cortex of the rice root. This provides an improved understanding of the element homeostasis in rice with biochar-mineral fertilization.

${ }^{1}$ National-Regional Joint Engineering Research Center for Soil Pollution Control and Remediation in South China, Guangdong Key Laboratory of Integrated Agro-Environmental Pollution Control and Management, Institute of Eco-Environmental and Soil Sciences, Guangdong Academy of Sciences, Guangzhou 510650, China. ${ }^{2}$ School of Materials Science and Engineering, University of New South Wales, Sydney, NSW 2052, Australia. ${ }^{3}$ Mark Wainwright Analytical Centre, University of New South Wales, Sydney, NSW 2052, Australia. ${ }^{4}$ Electron Microscopy Centre, AlIM Building, Innovation Campus, University of Wollongong, North Wollongong, NSW 2517, Australia. ${ }^{5}$ College of Resources and Environmental Sciences, Nanjing Agricultural University, Nanjing, 210095, China. ${ }^{6}$ Institute for Superconducting and Electronic Materials and School of Physics, University of Wollongong, Wollongong, NSW 2522, Australia. ${ }^{\square}$ email: ghchen@soil.gd.cn; joey.stephen@gmail.com 
Rice (Oryza sativa L.), which serves as the dietary staple for half the world's population, has experienced increasing demand with global population growth ${ }^{1}$. Rice is normally cultivated in flooded paddy soil, and takes up essential and beneficial mineral elements for growth ${ }^{2}$. Under anaerobic conditions, with high levels of iron (II) $\left(\mathrm{Fe}^{2+}\right)$, Fe homeostasis plays an essential role in many cellular functions of the plant, and can provide protection from toxicity of free-form $\mathrm{Fe}$ as catalyst of the Fenton reaction ${ }^{3}$. Fe-rich plaque was formed around the rice root by rhizosphere oxygenation following radial oxygen loss through root aerenchyma to the root surface and oxidation of $\mathrm{Fe}(\mathrm{II})$ at the root surface (i.e., biologically-induced biomineralization) ${ }^{4}$. Further, rice roots can take up $\mathrm{Fe}^{3+}$ by phytosiderophore, and $\mathrm{Fe}^{2+}$ followed by Fe chelation and reduction ${ }^{5}$. To store $\mathrm{Fe}$ in a safe and bioavailabile form, the iron oxide nanoparticles (such as ferrihydrite $\left(5 \mathrm{Fe}_{2} \mathrm{O}_{3} \cdot 9 \mathrm{H}_{2} \mathrm{O}\right)$ in ferritin) are formed in the cytocol and organelles of the root (i.e., matrix-mediated biomineralization) ${ }^{6}$.

Biochar amendments, such as wheat straw-derived biochar, have been reported to increase rice yield through improving the physical and biochemical properties of the soil and have been widely applied in paddy fields ${ }^{7-9}$. The biochars produced from wheat straw, one of the most abundant crop residues ${ }^{10}$, are enriched with silicon (Si) and thereby have a beneficial effects on plants ${ }^{11}$. It has been reported that biochars prepared through slow pyrolysis enhanced plant growth by their liming effect and high nutrient availability ${ }^{12,13}$. Combining Fe-rich minerals (e.g., $\mathrm{FeSO}_{4}$ and $\mathrm{Fe}_{2} \mathrm{O}_{3}$ ), together with chemical compounds containing nitrogen $(\mathrm{N})$ and phosphorus $(\mathrm{P})$, biochar-based fertilizers produced at relatively low temperature $\left(350-450^{\circ} \mathrm{C}\right)$ through slow pyrolysis possessed a high concentration of carbon (C)-containing functional groups (e.g., carboxylic $\mathrm{C}$ ) and dissolved organic matter, which was allowed to be more bioavailable to soil microbes and was higher redox active in the rhizosphere ${ }^{14}$. Previous research has shown that application of Fe-enhanced biochar can promote the formation of Fe-rich plaque and increase Fe accumulation in rice plants, and alter the uptake, transportation and accumulation of other mineral nutrients (e.g., $\mathrm{N}$ and $\mathrm{P}$ ) as well as toxic trace elements (e.g., Cd and As) in rice plants ${ }^{15-17}$. Our previous study revealed that the $\mathrm{Fe}$ - and Si-enhanced biochar enable to induce higher rice yield and $\mathrm{N}$ and $\mathrm{P}$ use efficiency relative to conventional chemical fertilizer, which was attributed to the greater plant uptake of mineral nutrients via the increased soil $\mathrm{Eh}$ and plant-growth promoting bacteria ${ }^{15}$. With response to the alteration of mineral nutrient status in root, element homeostasis (e.g., Fe) of rice root has been often analyzed by molecular genetic approaches ${ }^{18}$. Despite the importance of biomineralization in regulating cytoplasmic free mineral ions in plant, there is limited research on the in situ characteristics of biominerals formed on the plaque layer and in the cortex in the biochar-treated rice roots at the micron and sub-micron scale.

Microscopic and spectroscopic techniques enable spatial distribution, concentration, and chemical speciation on mineral elements in plant tissues to be determined. Scanning electron microscopy coupled with energydispersive spectroscopy (SEM-EDS) was the traditional method to detect the composition of macronutrients that accumulate to high concentration within plant tissues ${ }^{19}$. Energy-dispersive X-ray microanalysis (EDS) of the interface between a wheat root and Fe-enriched biochar particle showed that high concentrations of Fe, $\mathrm{Mn}$, $\mathrm{Si}$, and $\mathrm{Ca}$, and significant concentrations of $\mathrm{P}, \mathrm{Mg}, \mathrm{Al}$, and $\mathrm{K}$ were present $\mathrm{t}^{20}$. The same approach was used to characterise the Fe biominerals in Imperata cylindrica, an Fe hyperaccumulator, and this study showed crystalline Fe-containing phases formed in the root xylem vessels ${ }^{21}$. Transmission electron microscopy (TEM) coupled with EDS or electron energy-loss spectroscopy (EELS) analyses can be used to determine the chemical elements present and their speciation in plant tissues with high spatial resolution and sensitivity, such as a copper complex bound to a cell wall ${ }^{22}$, and Fe-bearing particles in the organelles and vacuoles of root cells ${ }^{23}$. TEM has been used to show the subcellular location of nanoparticles in plant root tissue exposed to Fe oxide nanoparticles ${ }^{24}$. TEMEDS analysis of root section of Imperata cylindrica showed Fe crystalline deposits with a high concentration of Fe in the root cell wall ${ }^{25}$. Advanced scanning transmission electron microscopy (STEM), coupled with energy electron loss spectroscopy (EELS), has been used to demonstrate the phase structure and oxidative states of nanoparticles in biological tissues ${ }^{26}$. Advanced STEM-EDS/EELS analysis has the capability to characterise the composition and speciation of biominerals at near nanometer scale within plant root tissue.

An imaging mass spectrometry approach, time-of-flight secondary ionization mass spectrometry (ToF-SIMS), has been utilized to verify the elemental and molecular distribution within plant tissues ${ }^{27}$. ToF-SIMS analysis revealed the distribution of elements such as $\mathrm{Si}, \mathrm{Al}, \mathrm{Fe}, \mathrm{Ca}, \mathrm{Mg}, \mathrm{Na}$, and $\mathrm{K}$ at the interface of tree roots with soil ${ }^{28}$, metals ions in wood tissue sections ${ }^{29}$, and coniferin distributions in ginkgo stems ${ }^{27}$. Another mass spectrometrybased technique is laser ablation inductively coupled plasma mass spectrometry (LA-ICP-MS) which can provide semiquantitative trace analysis of essential and toxic elements in plant tissues ${ }^{30}$. LA-ICP-MS analysis has been used to detect $\mathrm{Cu}$ and $\mathrm{Zn}$ in the surface tissues of cucumber $\operatorname{root}^{31}$.

The objective of this study is to utilize all these complementary characterization techniques to identify biochar-induced effects on nutrient accumulation in roots and the concomitantly formed Fe- and Si-rich biominerals in, or on, the rice root treated with the Fe- and Si-enhanced wheat straw biochar. The in situ composition, distribution and speciation of biominerals within plaque layers and inside the cortex of rice roots at micron- and sub-micron scale were studied using SEM-EDS, STEM-EDS/EELS, ToF-SIMS, LA-ICP-MS, and atomic force microscopy (AFM), as well as vibrating sample magnetometry (VSM) and Raman spectroscopy.

\section{Results}

Elemental concentration at the exterior and interior surfaces of root in the control or biochar-amended soil. With biochar addition, the mineral elements at the root interior were significantly higher than the surface, except for Al. At the root interior, there were significantly higher average concentration of nutrients in the biochar-treated root than the control root, such as Fe (5048 vs. $1120 \mathrm{mg} \mathrm{kg}^{-1}$ dry weight), Si (38,781 vs. $16,103 \mathrm{mg} \mathrm{kg}^{-1}$ dry weight), and $\mathrm{P}$ (16,050 vs. $5495 \mathrm{mg} \mathrm{kg}^{-1}$ dry weight) (Fig. 1). The concentrations of $\mathrm{Ca}, \mathrm{K}, \mathrm{Mg}, \mathrm{B}, \mathrm{Zn}$, and $\mathrm{Al}$ were also found to increase significantly inside the biochar-treated root (cf. control), while the Mn was not affected by biochar addition. To reveal the characteristics of biominerals formed in 
(a)

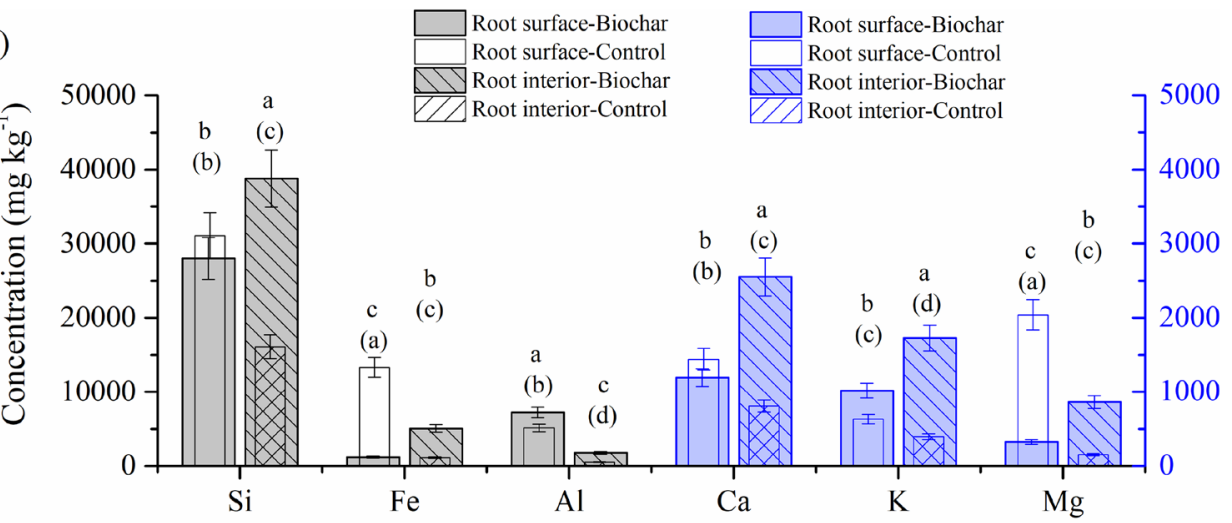

(b)

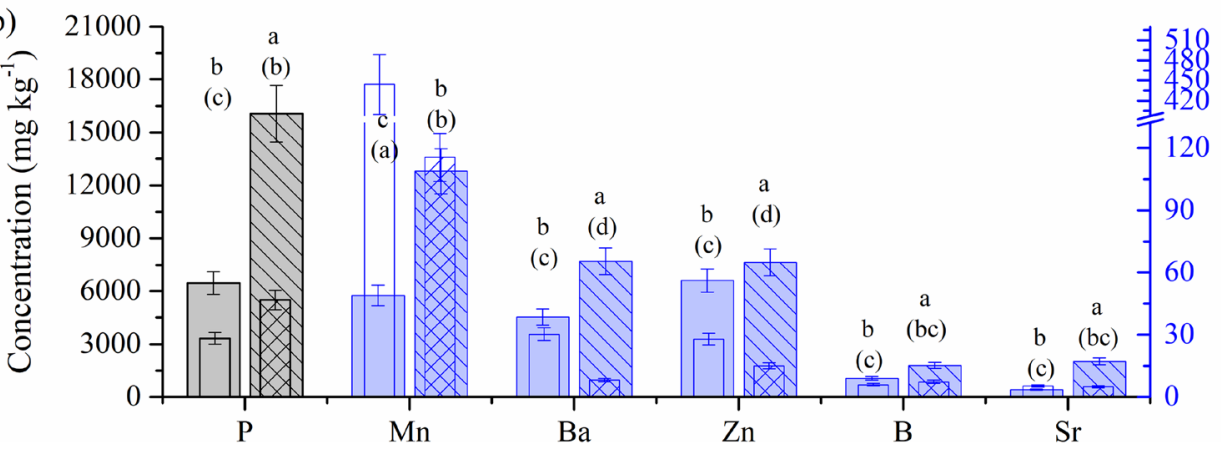

Figure 1. Total elemental concentrations (derived from LA-ICP-MS) of (a) $\mathrm{Si}, \mathrm{Fe}, \mathrm{Al}, \mathrm{Ca}, \mathrm{K}$, and $\mathrm{Mg}$ and (b) $\mathrm{P}, \mathrm{Mn}, \mathrm{Ba}, \mathrm{Zn}, \mathrm{B}$, and $\mathrm{Sr}$ at the surface and interior of the rice root in the control and biochar treatment. Error bars show standard deviation of three repeated measurements. Different lowercase letters indicate significant difference between the control (in brackets) and biochar treatment for each element $(P<0.05)$.

rice root containing high $\mathrm{Fe}$ and $\mathrm{Si}$ concentrations following biochar treatment, the elemental composition and speciation at the surface and interior of biochar-treated root were detected at the micron and sub-micron scale.

Elemental composition at the exterior and interior surfaces of the biochar-treated rice root. A magnetic hysteresis loop of a root sample is shown in Fig. S1a. Magnetic field strength was applied in the range of -5000 to 5000 Oe. The S-shaped curve with saturation magnetization value of $0.052 \mathrm{emu} \mathrm{g}^{-1}$ at 5000 Oe showed weak superparamagnetic behavior of the roots. The coercive field of the root was 58 Oe. Figure S1b shows a Raman spectrum from dark aggregates attached to the root surface. Two overlapping Raman bands at $1350 \mathrm{~cm}^{-1}$ (D band) and $1580 \mathrm{~cm}^{-1}$ ( $\mathrm{G}$ band) were assigned to the in-plane vibrations of a sp $\mathrm{sponded}^{2}$ carbon structure, which is characteristic of amorphous char structure in biochar particles (Fig. S1b) ${ }^{32}$. Raman D band is activated by structural disorder in graphitic structures and it corresponds to breathing modes of carbon $\mathrm{sp}^{2}$ rings. The $\mathrm{G}$ band corresponds to the in-plane stretching vibrations of $\mathrm{C}-\mathrm{C}$ bonds in graphitic systems and it does not require structural disorder to become Raman active. Raman mapping of the $G$ band showed that micron-sized biochar particles (originally $<25 \mu \mathrm{m}$ in size) appeared to form aggregates, ranging in size from $<10$ up to $40 \mu \mathrm{m}$ (Fig. S1c-inset). Dark regions were produced by detector saturation from autofluorescence.

Elemental compositions in the roots were further characterised using ToF-SIMS measurements in both positive and negative modes. ToF-SIMS revealed that the relative concentrations of $\mathrm{FeO}_{2}{ }^{-}, \mathrm{FeO}_{2} \mathrm{H}^{-}, \mathrm{FeO}_{3}{ }^{-}$, and $\mathrm{FeO}_{3} \mathrm{H}^{-}$anions (Fig. 2a), as well as S-bearing anions (Fig. 2f) at the interior surface of the root were generally lower in concentration than those at the exterior root surface. However, the ions of $\mathrm{Ca}, \mathrm{Mg}, \mathrm{Si}, \mathrm{Al}$, and $\mathrm{C}$ were more abundant at the interior than the exterior (Fig. 2b-e). The most abundant Fe- and Al-bearing ions were $\mathrm{Fe}^{+}(0.035-0.84 \%)$ and $\mathrm{Al}^{+}(0.030-5.5 \%)$. The dominant $\mathrm{Si}$-bearing ion liberated from the root was $\mathrm{SiHO}_{3}{ }^{-}(0.089-1.8 \%)$ followed by $\mathrm{Si}^{+}(0.035-1.2 \%)$. While $\mathrm{SiHO}_{3}{ }^{-}$and $\mathrm{SiHO}_{2}{ }^{-}$anions indicated the presence of hydrated amorphous $\mathrm{Si}$ compounds, the $\mathrm{Si}^{+}$cation corresponded to silicates. Anions of $\mathrm{C}_{2} \mathrm{H}^{-}, \mathrm{CN}^{-}$, and $\mathrm{CNO}^{-}$were derived from organic phases that were abundant in the root. In addition, the sulfur oxide anions, mainly $\mathrm{SO}_{3}{ }^{-}$and $\mathrm{SO}_{4}{ }^{-}$, were also present at both the exterior and interior regions of the root.

ToF-SIMS measures the outermost monolayer of a sample surface to determine micron-scale distributions of elements and molecules. Mapping the intensity of the $\mathrm{CN}^{-}$and $\mathrm{CNO}^{-}$anions produces an image of the protein distribution in the interior and exterior surface of the root (Figs. 3a and 4a). Silicon-bearing ions yielded a strong signal in some regions of the root exterior (Fig. 3b). The spatial distributions of Fe- and Al-bearing ions mainly coincided with the distributions of Si-bearing ions. SEM imaging was undertaken on the same regions as those analysed by ToF-SIMS (Fig. 3c). The analysis revealed that some large organomineral composites were formed on the root surface. EDS mapping showed that regions which were rich in Fe and those rich in Si did not coincide exactly, whereas Al-rich clusters were restricted to either the Fe- or Si-rich regions (Fig. 3d). Elemental 

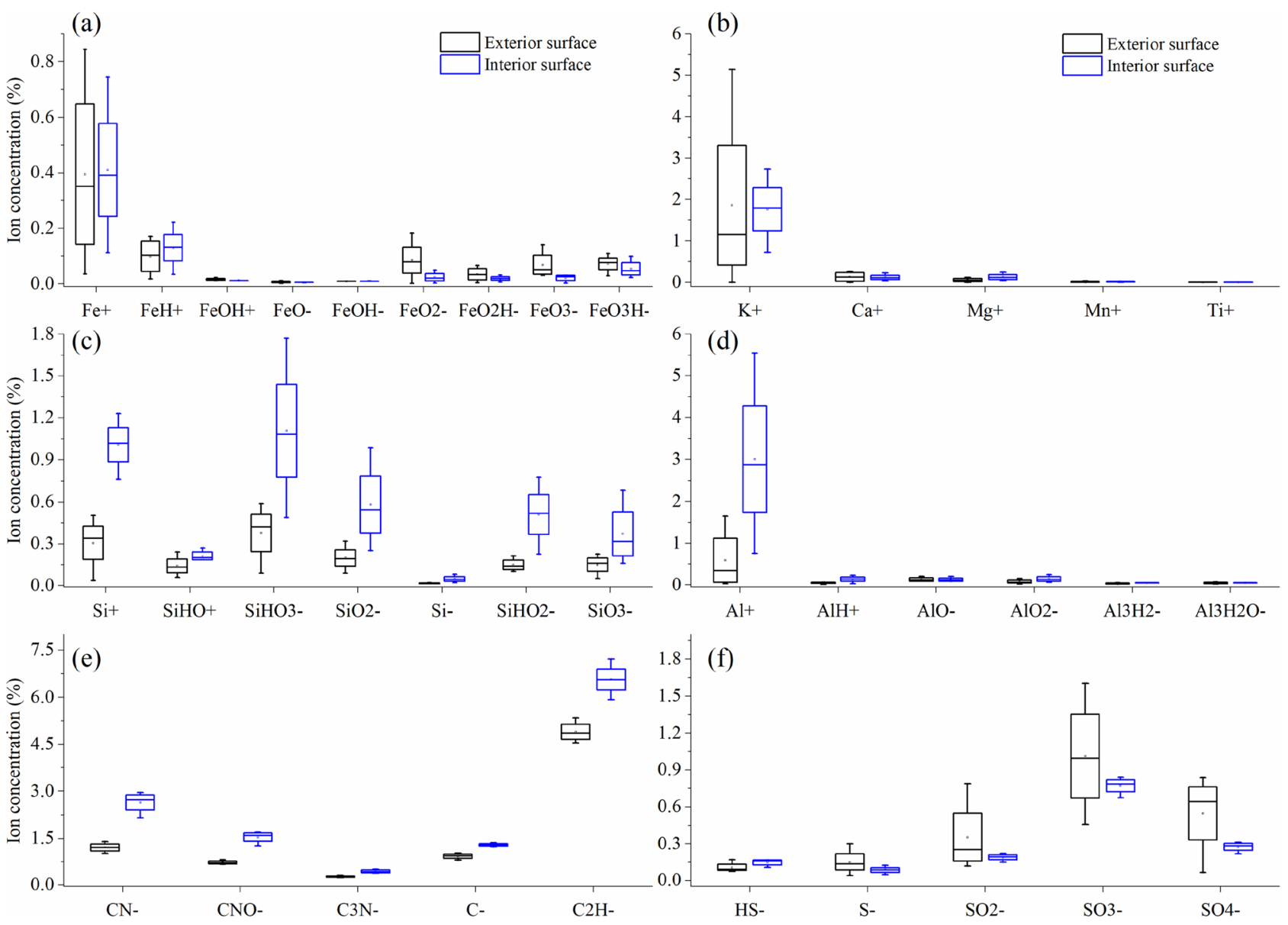

Figure 2. Box plots of relative concentrations of (a) Fe-bearing ions, (b) K, Ca, Mg, Mn, and Ti cations, (c) Si-bearing ions, (d) Al-bearing ions, (e) C-bearing anions, and (f) S-bearing anions, at the exterior and interior surface of the biochar-treated rice root detected by ToF-SIMS. Each plot represents readings from five locations randomly selected in a single specimen.

concentrations analyzed by EDS spectroscopy were ranked in order: $\mathrm{P}>\mathrm{Si}>\mathrm{Al}>\mathrm{Fe}$ (Fig. $3 \mathrm{e}$ ), although more precise quantification of such a matrix was not feasible. Based on the results of SEM-EDS, Fe-containing aggregates on the root exterior ranged in size from a few to over $100 \mu \mathrm{m}$ in diameter, indicative of Fe-rich plaque present on the root surface. At the interior surface of the root, the ToF-SIMS analysis showed that Fe-, Al- and Si-bearing ions correlated with the presence of $\mathrm{CN}^{-}$and $\mathrm{CNO}^{-}$(Fig. 4a,b). SEM-EDS results showed that Fe appeared to be highly localised within regions $<1 \mu \mathrm{m}$ in size (Fig. $4 \mathrm{c}, \mathrm{d}$ ). High concentrations of $\mathrm{Si}, \mathrm{P}, \mathrm{Na}$, and $\mathrm{Al}$ with significant concentrations of $\mathrm{Fe}, \mathrm{Mg}, \mathrm{K}$, and $\mathrm{S}$ within the root interior were also observed by EDS analysis (Fig. 4e).

Elemental speciation of extracellular and intracellular components of the biochar-treated rice root. Examination of a stained transverse section of the root by STEM-EDS/EELS revealed the speciation of nanocomposites at the sub-micron scale. Ultrastructural observations (Fig. 5a and Fig. S2) showed that microbes (approximately circular in cross section) with a size of around $0.3 \mu \mathrm{m}$ were bound to the root epidermis (bottom of the image). Two regions of interest were further analyzed by EDS/EELS. The EDS spectra from Region 1 showed a high concentration of $\mathrm{Si}$ with small amounts of Fe at the surface layer of the microbe, and Region 2 showed significant concentrations of $\mathrm{Si}, \mathrm{Fe}$, and $\mathrm{P}$ at the microbe-root interface. The interface between the microbe and root, a region approximately $100 \mathrm{~nm}$ wide (region 2), was analyzed by EELS-the Fe L-edge is shown inset in Fig. 5a. There was a sharp peak at $\sim 712.0 \mathrm{eV}$ in the Fe L-edge, suggesting iron in a Fe(III) oxidation state. In the interior of the root, intracellular agglomerates were visualized by high-angle annular dark field (HAADF) imaging (bright regions in Fig. 5b). The EDS spectrum from the region arrowed is shown as an inset where a high concentration of Fe was detected. A magnified bright field (BF) image of the agglomerate showed that matrices contained an Fe-rich core with a diameter of around $5 \mathrm{~nm}$ (Fig. $5 \mathrm{c}$ ). Additionally, there were intracellular particle clusters shown in the BF image (Fig. 5d) and high concentrations of Si and Fe were detected by EDS analysis (Fig. 5d-inset). A detailed view of the clusters showed the presence of needle-like particles (Fig. 5e). The corresponding Fe L-edge EEL spectrum (inset) showed that the $\mathrm{Fe}_{3}$ edge had maximum at $\sim 712.8 \mathrm{eV}$ with a split edge typical for Fe minerals with a mixed oxidation states (Fe(II)/Fe(III)) (Fig. 5e-inset). 

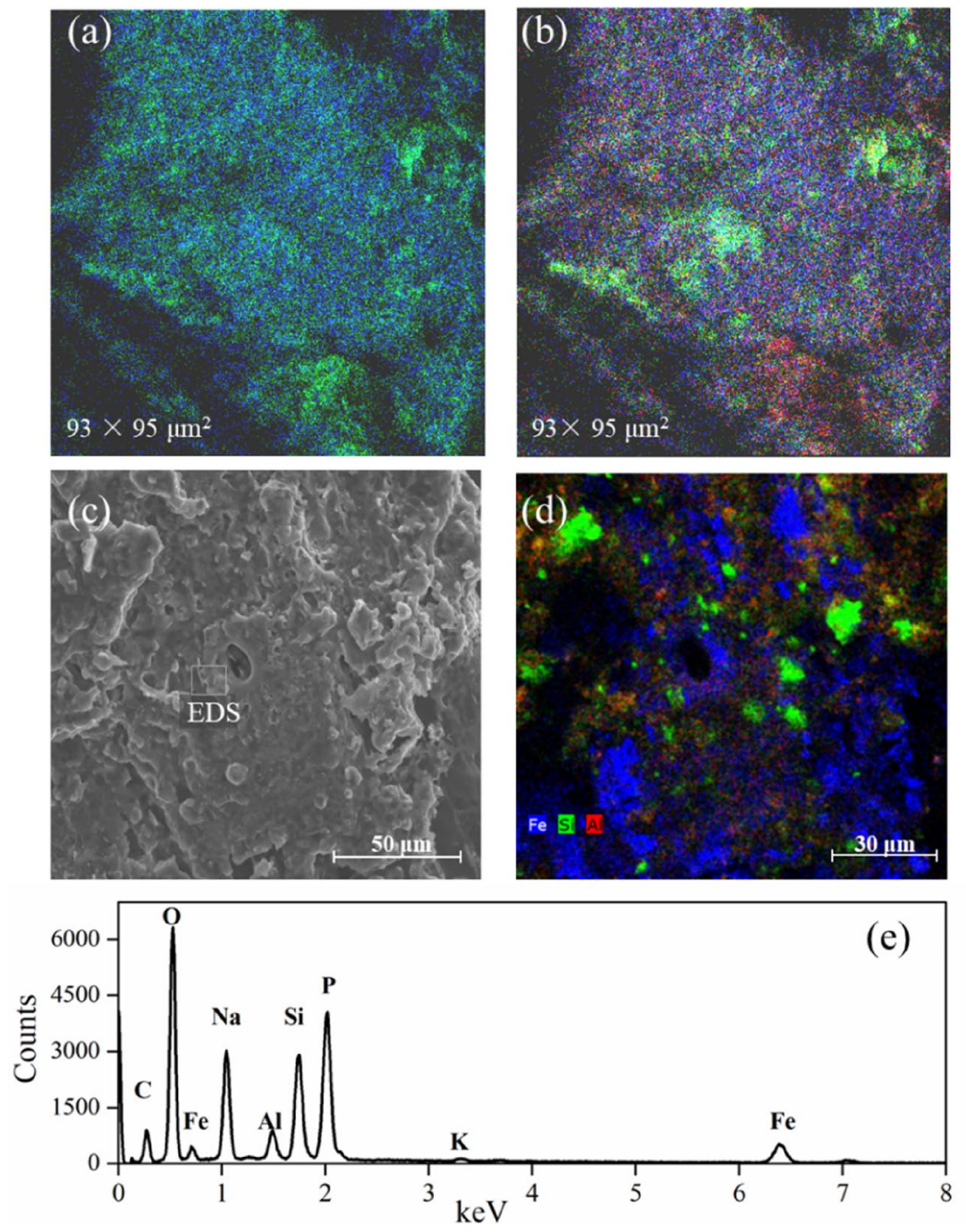

Figure 3. The morphology and elemental distribution at the exterior surface of the biochar-treated rice root. ToF-SIMS images of (a) the sum of $\mathrm{CN}^{-}$and $\mathrm{CNO}^{-}$(green) and Fe-bearing ions $\left(\mathrm{Fe}^{+}, \mathrm{FeH}^{+}, \mathrm{FeOH}^{+}, \mathrm{FeO}^{-}\right.$, $\mathrm{FeOH}^{-}, \mathrm{FeO}_{2}^{-}, \mathrm{FeO}_{2} \mathrm{H}^{-}, \mathrm{FeO}_{3}^{-}, \mathrm{FeO}_{3} \mathrm{H}^{-}$) (blue); and (b) the sum of Fe-bearing ions (blue), $\mathrm{Al}$-bearing ions $\left(\mathrm{Al}^{+}\right.$, $\left.\mathrm{AlH}^{+}, \mathrm{AlO}^{-}, \mathrm{AlO}_{2}^{-}, \mathrm{Al}_{3} \mathrm{H}_{2}^{-}, \mathrm{Al}_{3} \mathrm{H}_{2} \mathrm{O}^{-}\right)$(red) and Si-bearing ions $\left(\mathrm{Si}^{+}, \mathrm{SiHO}^{+}, \mathrm{SiO}_{2}^{-}, \mathrm{SiHO}_{3}^{-}, \mathrm{Si}^{-}, \mathrm{SiHO}_{2}^{-}, \mathrm{SiO}_{3}^{-}\right)$ (green). (c) SEM secondary electron image of the exterior surface of the root and (d) EDS mapping showing the elemental distribution of $\mathrm{Fe}, \mathrm{Al}$, and $\mathrm{Si}$, and (e) EDS spectrum obtained from the region of interest in Fig. 4c, showing strong signals from $\mathrm{P}, \mathrm{Si}, \mathrm{Al}$ and $\mathrm{Fe}$.

Electric potential in the interior of biochar-treated rice root. The AFM in Kelvin probe mode (KPFM) visualized the surface topography of cross sections of root tissue to detect the in situ internal cell structure and mapped electrical potential. The AFM image showed the inner ultrastructure of the root, including the cell wall, vacuoles (V), cytoplasm (C), and mitochondria (M) (Fig. 6a). The thickness of the cell wall was approximately $0.2 \mu \mathrm{m}$ and intracellular structures were readily visible. The thin root section $(\sim 400 \mathrm{~nm})$ promoted good surface conductivity, improving the resolution of the AFM. The cellular electric potential was detectable as a surface potential (Fig. 6b). It was noted that electrically charged domains presented on a micron scale in the root interior and the potential varied between various internal root structures. The cell wall has a consistently lower surface potential (approximately $20-30 \mathrm{mV}$ ) than the cell interior (particularly vacuoles), while a more heterogeneous potential distribution was observed in the cytoplasm.

\section{Discussion}

The increased rice yield by the application of the Fe- and Si-enhanced biochar relative to conventional chemical fertilizer was reported ${ }^{15}$, and this was related to the higher plant uptake of mineral nutrients during the biocharroot interactions ${ }^{33,34}$. The presence of biochar particles on the root surface was identified by Raman spectroscopy. In this spectrum, the observed overlapping D and G band in the range from 1400 to $1550 \mathrm{~cm}^{-1}$ (Fig. S1b) is characteristic of the graphitic carbon matrix ${ }^{32}$. Raman mapping of the $\mathrm{G}$ band demonstrated that biochar particles were micron-sized (Fig. S1c). Through the direct interaction with biochar, plant roots can take up macro- and 

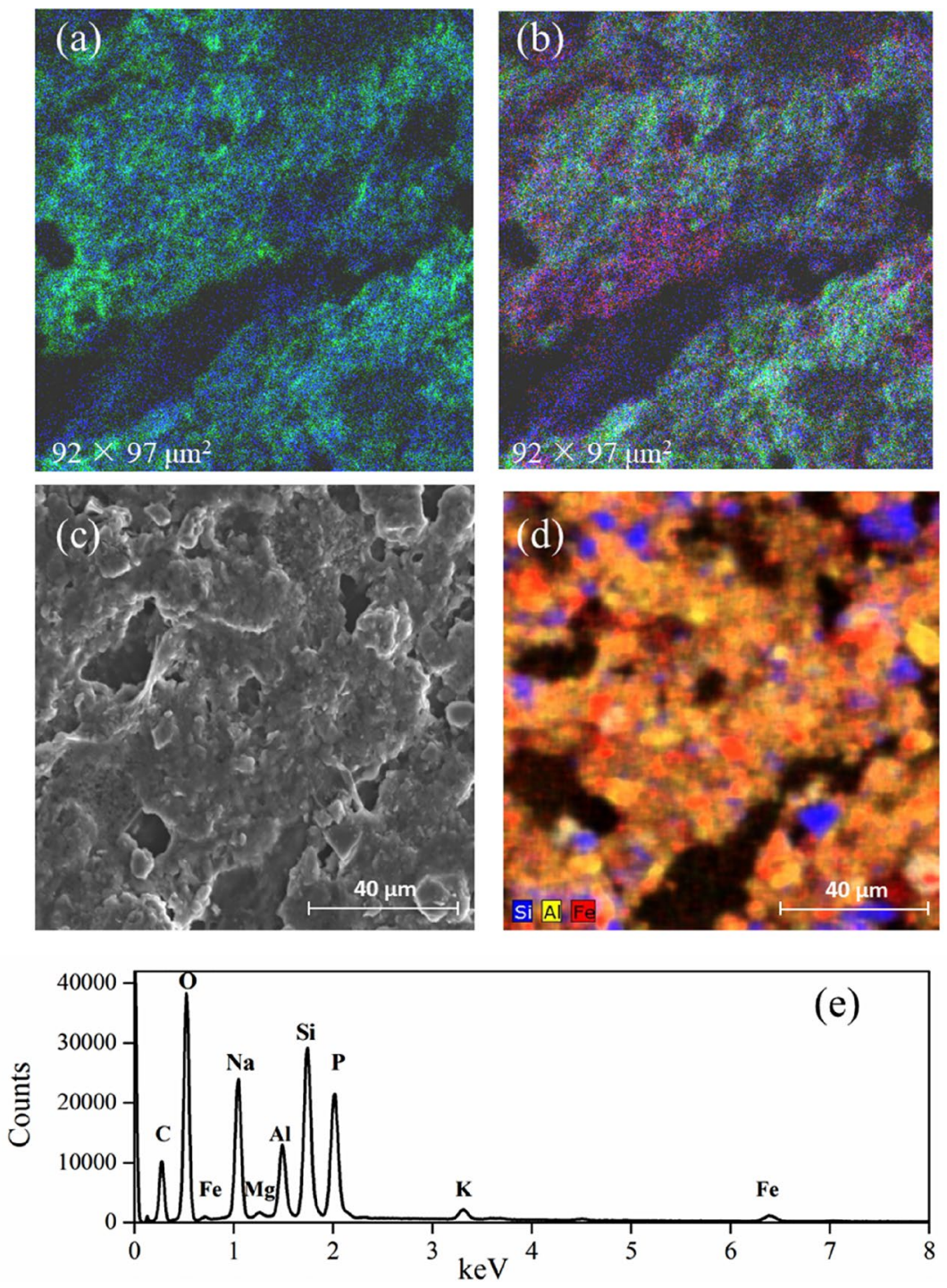

Figure 4. The morphology and elemental distribution at the interior surface of the biochar-treated rice root. ToF-SIMS images of (a) the sum of $\mathrm{CN}^{-}$and $\mathrm{CNO}^{-}$(green) and Fe-bearing ions $\left(\mathrm{Fe}^{+}, \mathrm{FeH}^{+}, \mathrm{FeOH}^{+}, \mathrm{FeO}^{-}\right.$, $\mathrm{FeOH}^{-}, \mathrm{FeO}_{2}^{-}, \mathrm{FeO}_{2} \mathrm{H}^{-}, \mathrm{FeO}_{3}^{-}, \mathrm{FeO}_{3} \mathrm{H}^{-}$) (blue); and (b) the sum of Fe-bearing ions (blue), $\mathrm{Al}$-bearing ions $\left(\mathrm{Al}^{+}\right.$, $\left.\mathrm{AlH}^{+}, \mathrm{AlO}^{-}, \mathrm{AlO}_{2}^{-}, \mathrm{Al}_{3} \mathrm{H}_{2}^{-}, \mathrm{Al}_{3} \mathrm{H}_{2} \mathrm{O}^{-}\right)$(red) and Si-bearing ions $\left(\mathrm{Si}^{+}, \mathrm{SiHO}^{+}, \mathrm{SiO}_{2}^{-}, \mathrm{SiHO}_{3}^{-}, \mathrm{Si}^{-}, \mathrm{SiHO}_{2}^{-}, \mathrm{SiO}_{3}^{-}\right)$ (green). (c) SEM secondary electron image of the interior surface of the root and (d) EDS mapping showing the elemental distribution for $\mathrm{Fe}, \mathrm{Al}$, and $\mathrm{Si}$, (e) EDS spectrum obtained from the whole region shown in Fig. 5c, showing strong signals from $\mathrm{Si}, \mathrm{P}, \mathrm{Al}$, and $\mathrm{Fe}$.

micro-nutrients from the surface and from the pores of the biochar ${ }^{14,15,35}$. Significantly higher concentrations of Fe were observed inside the biochar-treated root than the control (Fig. 1), possibly due to additional Fe arising from the biochar, despite the biochar-induced increase in soil $\mathrm{pH}$ (from 5.4 to 6.4) counteracting, to some extent, the increased availability of Fe to plants. Compared with the root interior, the average concentrations of iron oxide derived species, i.e., $\mathrm{FeO}_{2}^{-}, \mathrm{FeO}_{2} \mathrm{H}^{-}, \mathrm{FeO}_{3}^{-}$, and $\mathrm{FeO}_{3} \mathrm{H}^{-}$anions, were greater at the surface of biochartreated root, as analyzed by ToF-SIMS (Fig. 2), revealing iron oxides and hydroxides formed in the plaque layer ${ }^{36}$. STEM-EELS analysis indicated that the Fe was in the $\mathrm{Fe}$ (III) oxidation state. Comparison of the experimental EELS spectrum (Fig. 5a) with a reference EEL spectra for ferrihydrite $\left(5 \mathrm{Fe}_{2} \mathrm{O}_{3} \cdot 9 \mathrm{H}_{2} \mathrm{O}\right)$ showed a good match ${ }^{37}$. On the other hand, lower concentration of total Fe at root surface was caused by biochar addition (cf. control), likely due to the dilution of $\mathrm{Fe}$ in plaque layer with the increased other minerals (e.g., $\mathrm{P}$ ).

ToF-SIMS measurements showed that $\mathrm{SiO}_{\mathrm{x}}{ }^{-}$and $\mathrm{SO}_{\mathrm{x}}{ }^{-}$anions (Fig. 2), ascribed to silicate and sulphate, were located at the root surface. The silicates and sulphates can combine with iron to produce secondary mineral phases in the plaque ${ }^{38,39}$. STEM-EDS determined nanoscale $\mathrm{Fe}-\mathrm{Si}-\mathrm{P}$ association occurred on the root surface, and suggested that in Fe plaque ferrihydrite bears both Si and P at trace levels (Fig. 5a). ToF-SIMS mapping also supported the co-location of Fe- and Si-bearing ions (Fig. 3b). In SEM-EDS analysis, however, the Si and Fe distributions did not completely correlate at the exterior surface of the root (Fig. $3 \mathrm{~d}$ ). These differences may 

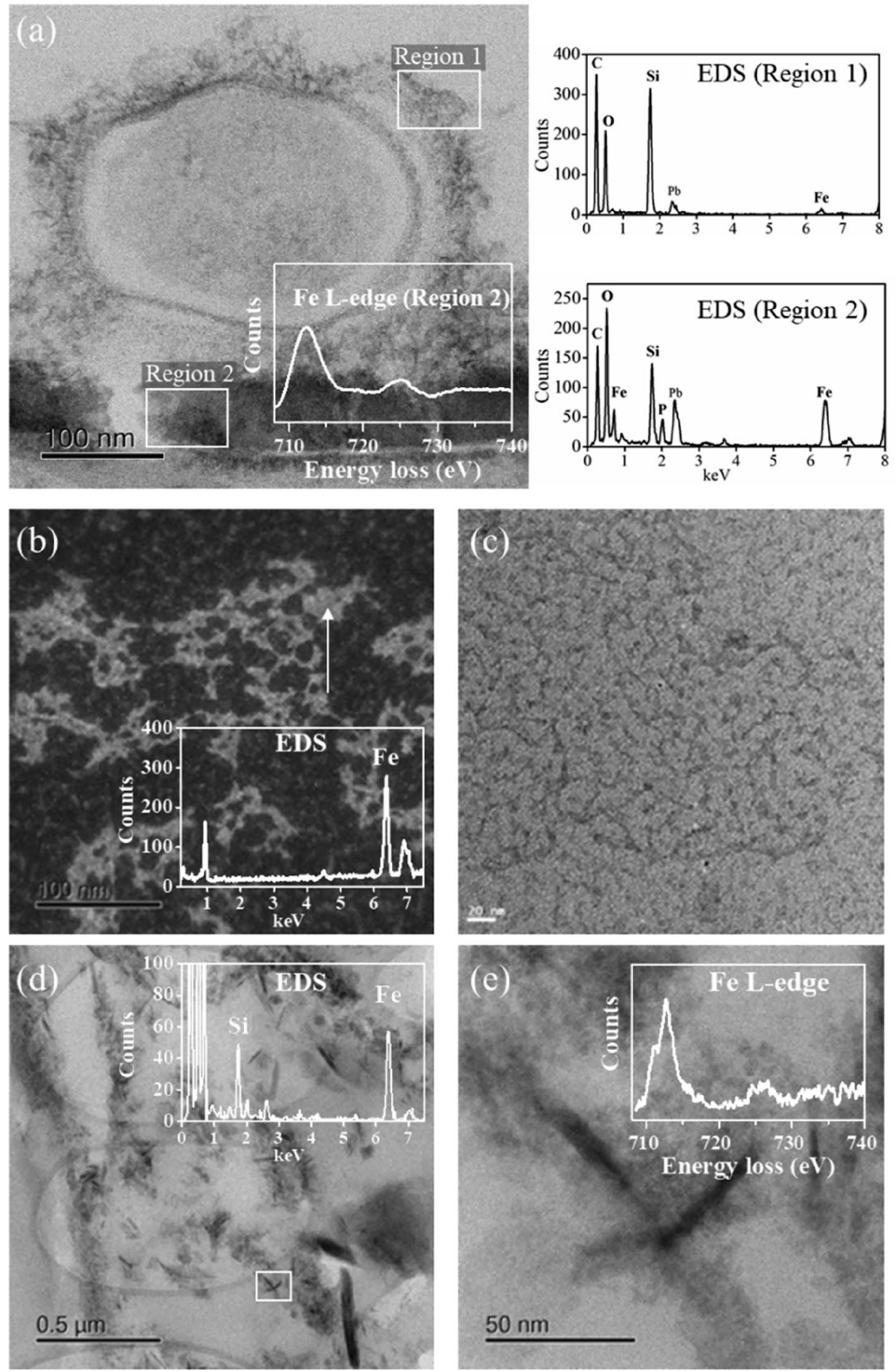

Figure 5. STEM analyses of a transverse section of a rice root exposed to enhanced biochar. (a) Bright field (BF) image of a microbe attached to the root epidermis. The two rectangular regions of interest are where EDS/EELS analyses were performed. The EDS spectra show a concentration of Si with small amounts of Fe at the surface layer of the microbe (Region 1), and significant concentrations of $\mathrm{Si}, \mathrm{Fe}$, and $\mathrm{P}$ at the microberoot interface (Region 2). The Fe L-edge EEL spectrum of region 2 is shown inset in (a) where the edge shape is typical of $\mathrm{Fe}_{3} \mathrm{O}_{4}$. (b) High-angle annular dark field (HAADF) image of the intracellular agglomerate of the root. The EDS spectrum from the region arrowed is shown inset where a high concentration of $\mathrm{Fe}$ is detected. (c) A magnified BF image of the agglomerate showing matrices containing an iron-rich core with a diameter of around $5 \mathrm{~nm}$. (d) BF image of an intracellular cluster of particles showing high concentrations of $\mathrm{Si}$ and $\mathrm{Fe}$ detected by EDS analysis. (e) Detailed view of the boxed region in (d) showing the needle-like particles, with the inset showing the Fe L-edge EEL spectrum typical for iron minerals with mixed oxidation states ( $\mathrm{Fe}(\mathrm{II}) / \mathrm{Fe}(\mathrm{III})$ ). 

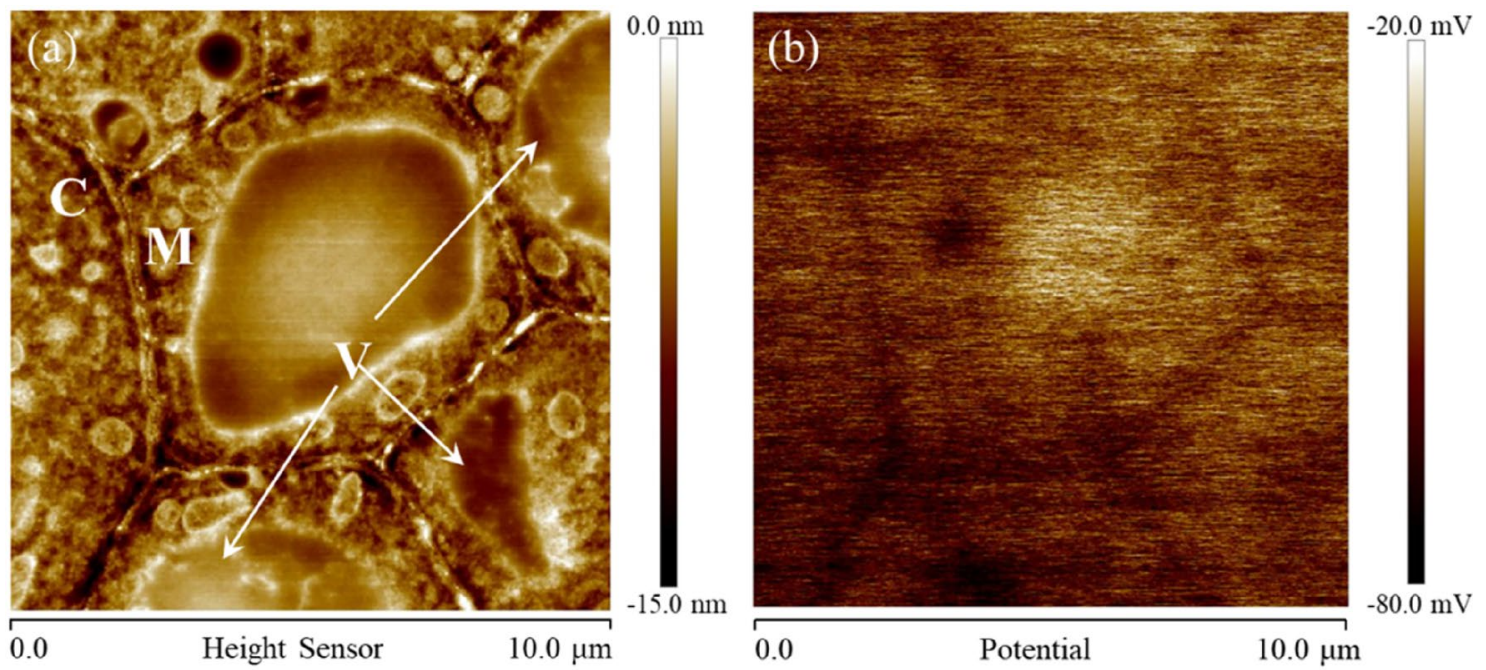

(c)

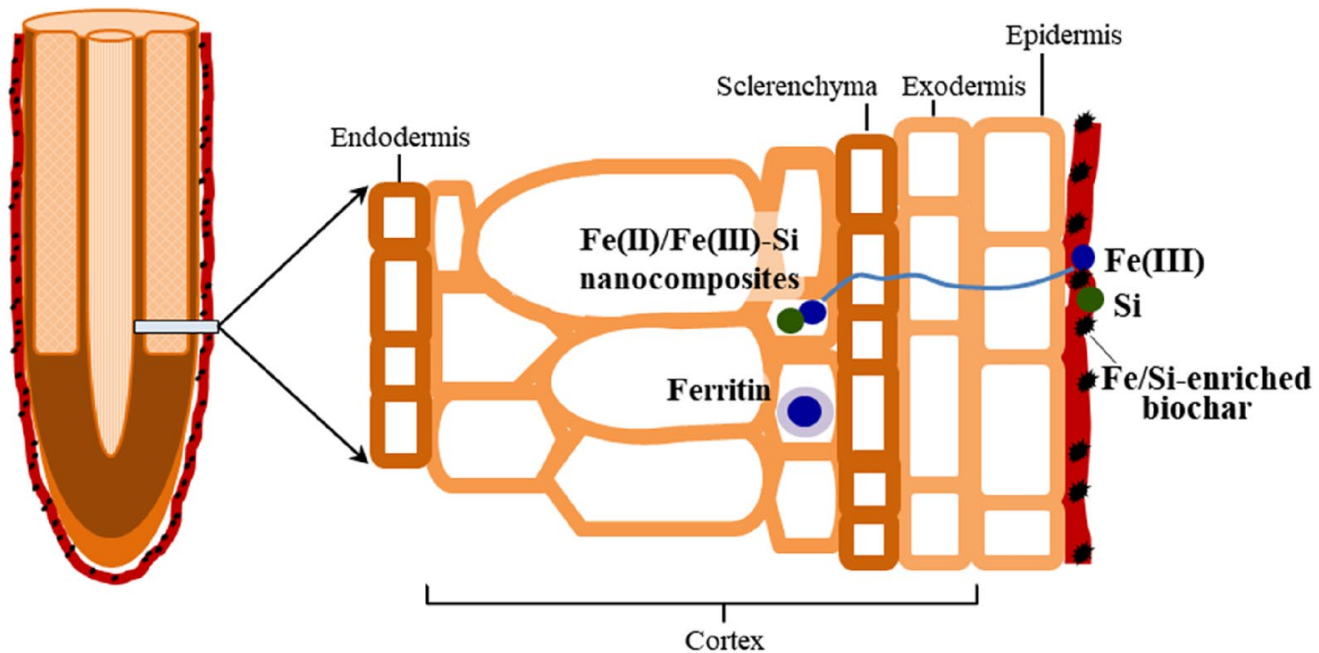

Figure 6. AFM images of a transverse section of a biochar-treated root embedded in resin. (a) Topographic image and (b) surface potential image. Internal cell structures including a vacuole (V), cytoplasm (C), and mitochondria $(\mathrm{M})$ are apparent. (c) Schematic diagram of the formation of a complex Fe/Si phase in iron plaque on the root surface and iron-rich nanocomposites and ferritin within the rice root amended with $\mathrm{Fe}$ - and Si-enhanced biochar.

stem from the fact that the EDS signal originates from the outer 1 to 5 microns of the specimen, while ToFSIMS measures a nanoscale surface monolayer ${ }^{40}$. When wheat straw biochar $\left(400^{\circ} \mathrm{C}\right)$ used in our study was enriched with $\mathrm{Si}$, the $\mathrm{Si}$ release from phytogenic $\mathrm{Si}$ occurred and could be favored by biochar-induced increase in soil $\mathrm{pH}^{11,41}$. The Fe- and Si-enhanced biochar could be considered as a Si source for the Si-bearing ions in the plaque layer, and might have contributed to increased root uptake of Si as analyzed by LA-ICP-MS (Fig. 1). Futhermore, the concentration of $\mathrm{P}$ at the root interior and exterior surface was significantly increased by biochar amendment (Fig. 1). Besides the additional $\mathrm{P}$ from the biochar, the soil $\mathrm{pH}$, increased by biochar additions, could increase $\mathrm{P}$ availability by reduced $\mathrm{P}$ sorption from soil (particularly $\mathrm{Fe}$ and $\mathrm{Al}$ oxides) ${ }^{42}$. Another proposed mechanism was the increase in activity of alkaline phosphatase or phosphodiesterase from microbes, which catalyzed the hydrolysis of esters and anhydrides of phosphoric acid, under liming ${ }^{43}$. With respect to the distribution of Al-bearing ions, $\mathrm{Al}$ was associated with the Fe plaque and possibly interacted with $\mathrm{Si}$ at the root exterior, as detected by both ToF-SIMS and SEM-EDS. The Al immobilization in the plaque might be due to the formation of aluminosilicate complexes and this could be favored with increasing soil $\mathrm{pH}$ through biochar additions ${ }^{44}$. Thus, with the Fe- and Si-enhanced biochar addition, Fe nanocomposites were embedded within the Fe plaque that can sequester and (subsequently) supply plant nutrients of $\mathrm{Fe}, \mathrm{P}, \mathrm{S}$, and $\mathrm{Si}$, and influence the availability of toxic metals ions (e.g., $\mathrm{Al})^{45}$.

Biochar-rhizosphere interactions can create microbial hotspots, which were defined as small soil volumes with high microbial activity and fast reaction rates, by the labile root exudates and the particulate biochar $\mathrm{C}^{46}$. Using STEM, microbes were found to be bound to the Fe-rich plaque in regions with significant concentrations of Fe, $\mathrm{Si}$ and $\mathrm{P}$ on the biochar-treated root surface (Fig. 5a). The wheat straw biochar used in our study contained 
a relatively high concentration of low molecular weight water soluble/volatile organic compounds, such as alkenes, alkanes aldehydes, ketones, acids and alcohols, and humic substances and polyphenols ${ }^{15}$. Biochar with redox-active moieties (e.g., (hydro)-quinones,) may act as an electron shuttle from the $\mathrm{C}$ substrate to less accessible electron acceptors (e.g., Fe), thus stimulating microbial degradation of organic matter (referred to as the "priming effect") ${ }^{33}$. The biochar-regulated electron transfer in redox reactions, such as the transformation of C, $\mathrm{N}$ and $\mathrm{S}$, can involve reactions with Fe species in the rhizosphere, and this might be one of mechanisms for the significantly increased presence of mineral nutrients in the rice root.

The potential AFM image revealed that the root cell wall had a consistently low potential (Fig. 6b), as it is composed of negatively charged polysaccharides. Silica uptake from biochar-amended soil by a rice root could accumulate in the cell wall, and subsequently form a negatively charged Si-hemicellulose complex which is more likely to bind cations ${ }^{47}$. Cation accumulation in the root cortex could have contributed to micron-sized electrically charged domains in the potential AFM image (Fig. 6b,c). At the root interior, the simultaneous presence of Fe, Al, and Si deposits has been observed by ToF-SIMS (Fig. 4b), indicating the formation of aluminosilicate, which could be responsible for the alleviation of $\mathrm{Al}$ toxicity by reducing $\mathrm{Al}$ transportation. Despite the observed increase of $\mathrm{Al}$ concentration in the biochar-treated root relative to the control (Fig. 1), the coprecipitation of $\mathrm{Al}$ with $\mathrm{Si}$ is regarded as part of the Al-tolerance strategies in plant ${ }^{48}$.

The nanoparticles $<50 \mathrm{~nm}$ from Fe- and Si-enhanced biochar-amended soil could be internalized and translocated through the symplastic pathways, according to the size exclusion limits imposed by chemical and physiological barriers of the root $^{49}$. There have been some recent studies on the morphology of iron oxide nanoparticles within plant roots ${ }^{24}$. Iron in the form of an oxyhydroxide or hydrated oxide species in rice root has been found by Mössbauer spectroscopic measurement of powdered root tissue in a study by Kilcoyne et al. ${ }^{6}$. To our knowledge, this is the first study that has investigated the in situ chemical speciation of intracellular Fe at the nanoscale with aberration-corrected STEM, providing information about the Fe biominerals within the internal structure of a biochar-treated rice root. STEM-EDS/EELS showed that Fe-bearing nanocomposites were present inside the root. These may be ferritin and other Fe-bearing nanoparticles (Fig. 5b,d). The $\sim 5 \mathrm{~nm}$ Fe core of ferritin was identified by STEM-EDS (Fig. 5b,c). As an Fe-storage protein, ferritin retains Fe in a safe and bioavailable form, providing intracellular control of Fe homeostasis ${ }^{3}$. In addition to ferritin, intracellular needle-like clusters of Fe nanoparticles, with diameters less than $50 \mathrm{~nm}$, which contained significant concentrations of Si were found (Fig. $5 \mathrm{~d}$ ); these may be aegirine $\left(\mathrm{NaFeSi}_{2} \mathrm{O}_{6}\right)$. EELS of this phase (Fig. 5e) suggested it had a mixed oxidation state $(\mathrm{Fe}(\mathrm{II}) / \mathrm{Fe}(\mathrm{III}))$ in the aegirine phase $\mathrm{e}^{50}$. The presence of Fe-containing magnetic nanoparticles in the biochartreated rice root were also supported by VSM, showing a small coercive field (58 Oe) in magnetic hysteresis loop (Fig. 1a) characteristic of magnetic nanoparticles with diameters of less than $50 \mathrm{~nm}^{51}$. The Fe-rich core of ferritin and intracellular Fe nanocomposites with mixed oxidation states suggested Fe storage via biomineralization in the biochar-treated rice $\operatorname{root}^{25}$. Therefore, with the Fe- and Si-enhanced biochar addition the biominerals were formed in contrasting species at the root exterior and interior, in relation to the mineral homeostasis in rice grown in biochar-fertilizer amended soil.

\section{Conclusions}

A range of advanced techniques were applied to reveal the increase of mineral nutrients and in situ charateristics of concomitantly formed Fe biominerals in rice roots treated with the Fe- and Si-enhanced biochar. LAICP-MS showed that the concentrations of mineral nutrients, e.g., Fe, Si, and P, in the root interior increased significantly by biochar treatment. Chemical distributions and speciation of mineral nanocomposites formed in biochar-treated root interior and exterior have been determined at the micron- and sub-micron scale. VSM magnetometry and Raman mapping permitted identification of micron-sized biochar particles and magnetic nanoparticles associated with the roots. ToF-SIMS and SEM-EDS analyses, revealed the formation of a complex $\mathrm{Fe}-\mathrm{Si}-\mathrm{P}$ phase in Fe plaque on the root surface. The sequestration of $\mathrm{Al}$ in this phase may reduce the transport of Al. STEM-EDS/EELS showed the presence of Fe-rich nanocomposites and possibly ferritin within the rice root. Additionally, the distribution of subcellular electric potential on a root section can be detected by AFM. These analyses demonstrate the power of such methods to characterize biominerals and provides insights into function of biomineralization in regulating element balance in plants amended with biochar-mineral fertilizer.

\section{Methods}

Biochar and soil. The Fe- and Si-enhanced biochar fertilizer was produced from a mixture of wheat straw, minerals and nutrients subjected to a relatively low temperature $\left(400{ }^{\circ} \mathrm{C}\right)$, which has been reported elsewhere to increase plant yield compared with conventional fertilizers ${ }^{15,52}$. A suspension of $5 \mathrm{~g} \mathrm{Fe}_{2} \mathrm{O}_{3}, 5 \mathrm{~g} \mathrm{FeSO}_{4} \cdot 7 \mathrm{H}_{2} \mathrm{O}$, $15 \mathrm{~g}$ rock phosphate, $15 \mathrm{~g}$ bentonite clay, and $15 \mathrm{~g}$ urea in $100 \mathrm{~mL}$ deionized water was prepared. Wheat straw $(200 \mathrm{~g})$ was mixed with the suspension at $80^{\circ} \mathrm{C}$ and the mixture left to stand for $24 \mathrm{~h}$ and then dried at $110^{\circ} \mathrm{C}$ for $3 \mathrm{~h}^{53}$. The modified biochar was produced by a slow pyrolysis process in a furnace under oxygen-limited conditions with a heating rate of $5{ }^{\circ} \mathrm{C} \mathrm{min}{ }^{-1}$, held at $400{ }^{\circ} \mathrm{C}$ for $30 \mathrm{~min}$, and then cooled to room temperature over a period of $24 \mathrm{~h}$. The detailed properties of this biochar are reported in the study of Chew et al. ${ }^{15}$. The C, N, K, and $\mathrm{P}$ composition (wt\%) in the biochar are: C 43\%; N 2.7\%; K 2\%; total P 1.4\%; citrate-extractable P $1.1 \%$. The $\mathrm{pH}$ of the biochar was 6.8 , with an acid neutralising capacity of $5.8 \%$ in calcium carbonate equivalents. The Feenriched bulk biochar included ferromagnetic and superparamagnetic iron oxide nanoparticles with diameters of $<10 \mathrm{~nm}$ and $>50 \mathrm{~nm}$, respectively, and sub-micron $\mathrm{SiO}_{2}$ particles.

The Fimi-Orthic Anthrosol was collected from the 0 to $15 \mathrm{~cm}$ layer from a rice paddy field in Nanjing, China $\left(31^{\circ} 58^{\prime} \mathrm{N}, 118^{\circ} 48^{\prime} \mathrm{E}\right)$. The soil was a clay-loam soil, The soil $\mathrm{pH}$ was 5.4 , EC $13.5 \mu \mathrm{S} \mathrm{cm}{ }^{-1}$, organic matter was $13.53 \mathrm{mg} \mathrm{g}^{-1}$. 


\begin{tabular}{|c|c|c|c|c|}
\hline Techniques & Lateral resolution & Sample preparation & Characteristics of biominerals & Results \\
\hline VSM magnetometry & n.a. & Critical point drying (CPD) & $\begin{array}{l}\text { Magnetic nanoparticles with diameters of less than } \\
50 \mathrm{~nm} \text { in the root }\end{array}$ & Fig. S1 \\
\hline Raman microspectroscopy & $\sim 1 \mu \mathrm{m}$ & CPD and longitudinal cutting & Micron-sized biochar particles on the root surface & Fig. S1 \\
\hline LA-ICP-MS & n.a. & Freeze drying and longitudinal cutting & $\begin{array}{l}\text { The plant nutrients (i.e., } \mathrm{Fe}, \mathrm{Si} \text {, and } \mathrm{P} \text { ) significantly } \\
\text { increased inside the biochar-treated root }\end{array}$ & Figure 1 \\
\hline ToF-SIMS & $\sim 100 \mathrm{~nm}$ & Freeze drying and longitudinal cutting & The iron oxides and hydroxides in the plaque layer & Figures 2,3 , and 4 \\
\hline SEM-EDX & $\sim 1 \mu \mathrm{m}$ & $\begin{array}{l}\text { CPD and longitudinal cutting and coating with } \\
\text { chromium }\end{array}$ & $\begin{array}{l}\text { Co-location of } \mathrm{Fe} \text { - and Si-bearing ions at the root } \\
\text { exterior and interior }\end{array}$ & Figures 3 and 4 \\
\hline STEM-EDX/EELS & $<0.14 \mathrm{~nm}$ & $\begin{array}{l}\text { Embedding in Spurr's resin and transverse cutting } \\
\text { by ultramicrotomy (thickness } \sim 60 \mathrm{~nm} \text { ) }\end{array}$ & $\begin{array}{l}\text { (1) Nanoscale Fe-Si-P association on the root } \\
\text { surface } \\
\text { (2) } \sim 5 \mathrm{~nm} \text { iron core of ferritin inside the root } \\
\text { (3) Intracellular needle-like clusters of iron nano- } \\
\text { particles in the aegirine phase }\end{array}$ & Figure 5 and Fig. S2 \\
\hline AFM & $\sim 100 \mathrm{~nm}$ & $\begin{array}{l}\text { Embedding in Spurr's resin and transverse cutting } \\
\text { by microtomy (thickness } \sim 400 \mathrm{~nm} \text { ) }\end{array}$ & $\begin{array}{l}\text { Micron-sized electrically charged domains inside } \\
\text { the root }\end{array}$ & Figure 6 \\
\hline
\end{tabular}

Table 1. Characterization techniques for biominerals formed in the exterior and interior surface of biochartreated root at micron- and sub-micron scale.

Rice plant growth. The plant growth experiment was carried out in $6.4 \mathrm{~L}$ boxes with three replicates. The box was divided into a central compartment with half of the total volume and two side compartments with one quarter of the total volume each. The compartments were separated using double nylon netting with a mesh size of $25 \mu \mathrm{m}$. The central compartment contained $2500 \mathrm{~g}$ soil, and side compartments were filled with a mixture of $1250 \mathrm{~g}$ soil, $12.5 \mathrm{~g}$ biochar, and $350 \mathrm{~g}\left(\mathrm{NH}_{4}\right)_{2} \mathrm{SO}_{4}$. Thus, only biochar and mineral particles with diameters of less than $25 \mu \mathrm{m}$ could migrate to the plant roots. There were biochar treatments $(n=3)$ and one control $(n=3)$. The chemical fertilizer was initially added into the soil with final concentrations of $\mathrm{N}(0.095 \%), \mathrm{P}(0.075 \%)$ and $\mathrm{K}$ $(3.8 \%)$, which was indicative of the control. The N, P and $\mathrm{K}$ in the biochar treatment $(0.095 \% \mathrm{~N}, 0.077 \% \mathrm{P}$, and $3.8 \% \mathrm{~K}$ ) were consistent with the control, as the increase of these macronutrients by biochar was negligible. Rice seedlings (Oryza sativa L.) were grown in the central compartment under flooded conditions for 30 days. Plants were placed in a greenhouse with a $14 / 10 \mathrm{~h}$ day/night photoperiod, at $30^{\circ} \mathrm{C} / 22^{\circ} \mathrm{C}$ day/night, light intensity of $400 \mu \mathrm{mol}$ photons $\mathrm{m}^{-2} \mathrm{~s}^{-1}$, and a relative humidity of $65-70 \%$.

Magnetic properties. Information on sample preparation and characterization techniques of the root sample is given in Table 1, which summarizes the microscopic, spectroscopic and mass spectrometric techniques used. The roots were sampled at harvest on day 30 , then washed with deionized water and dried by critical point drying (CPD). Magnetic studies were performed with a vibrating sample magnetometer (VSM) from Quantum Design Physical Property Measurement System. Magnetic hysteresis loops were obtained at room temperature $(300 \mathrm{~K})$ using a VSM vibration frequency of $40 \mathrm{~Hz}$ and an amplitude of $2 \mathrm{~mm}$. The sweep rate of the field was $100 \mathrm{Oe} \mathrm{s}^{-1}$.

Raman microspectroscopy. The $1 \mathrm{~cm}$ long root samples after CPD were cut longitudinally and used for analysis. To identify the principal carbonaceous particles attached to the exterior surface of the root, Raman spectroscopy was performed using an inVia Raman microspectrometer (Renishaw, UK) using a $532 \mathrm{~nm}$ excitation source. Raman imaging was obtained using the StreamHR mode, over a $100 \times 100 \mu \mathrm{m}$ area, with a $20 \times$ objective, $10 \%$ laser power (approximately $3.4 \mathrm{~mW}$ ) with a $1 \mathrm{~s}$ exposure and a $500 \mathrm{~nm}$ step size. A map of the biochar particles' Raman band at $1580 \mathrm{~cm}^{-1}$ on the root surface was collected using the WiRE software (Renishaw, UK).

Laser ablation inductively coupled plasma mass spectrometry (LA-ICP-MS) and time-of-flight secondary ionization mass spectrometry (ToF-SIMS). The longitudinal root sections were prepared as described above. The total concentrations of macronutrients (i.e., $\mathrm{P}, \mathrm{K}, \mathrm{Ca}, \mathrm{Mg}$, and $\mathrm{Fe}$ ) and micronutrients (i.e., $\mathrm{Mn}, \mathrm{B}$, and $\mathrm{Zn}$ ), as well as $\mathrm{Si}, \mathrm{Na}, \mathrm{Al}, \mathrm{Sr}$, and $\mathrm{Ba}$ at the exterior and interior surfaces of the root section were determined by LA-ICP-MS. The analysis was applied to randomly spots on each root using a NWR213 Laser Ablation unit (ESI New Wave, USA) coupled to a NexION 300D ICP-MS (Perkin Elmer, USA). Laser ablation parameters were as follows: wavelength $213 \mathrm{~nm}$, repetition frequency (RF) $10 \mathrm{~Hz}$, laser energy density $4.8 \mathrm{~J} \mathrm{~cm}^{-2}$ (at $30 \%$ ), spot size $110 \mu \mathrm{m}$, depth $1.5 \mu \mathrm{m}$ and scan speed $20 \mu \mathrm{m} \mathrm{s}^{-1}$. ICP-MS was performed at an RF power of $1150 \mathrm{~W}$, helium gas flow rate of $0.8 \mathrm{~L} \mathrm{~min}^{-1}$, argon gas flow rate of $0.6 \mathrm{~L} \mathrm{~min}^{-1}$ in peak hopping scan mode and with a dwell time of $0.05 \mathrm{~s}$. Elemental concentrations (calibrated against NIST610 and NIST612 glass standards) of the exterior and interior surfaces of the root were obtained in three separate $2 \mathrm{~mm}$ line scans for each area.

The molecular composition and distribution of the root interior and exterior on a sub-micron scale were measured using a ToF-SIMS 5 instrument (IONTOF GmbH, Germany) equipped with a bismuth liquid metal cluster ion gun as the primary ion source for analysis and an electron flood gun for charge compensation. Analysis was conducted using a $30 \mathrm{keV} \mathrm{Bi}_{3}{ }^{+}$cluster ion beam on root sections mounted onto silicon wafers. Data acquisition was performed over regions ranging in area between $100 \times 100$ and $200 \times 200 \mu \mathrm{m}^{2}$ to generate (1) elemental and molecular information in the form of an accummulated mass spectrum, and (2) two-dimensional images showing the intensity distribution of selected secondary ions from the areas analysed. 'Spectrometry' mode was used to acquire high-mass resolution spectra $(m / \Delta m>4000)$ for compositional analysis, and 'fast 
imaging' mode was used to acquire high spatial resolution images (lateral resolution $\sim 200 \mathrm{~nm}, m / \Delta m \sim 200$ ). To be consistent, both positive and negative spectra and images were collected from the same areas, resulting in four sets of data for each area analysed. Care was taken to ensure the total ion dose density from the four sets of scans was within the static SIMS limit $\left(10^{12}\right.$ primary ions per $\left.\mathrm{cm}^{2}\right)$. High-mass resolution positive spectra were calibrated using the masses of $\mathrm{CH}_{2}{ }^{+}, \mathrm{C}_{2} \mathrm{H}_{4}{ }^{+}, \mathrm{C}_{4} \mathrm{H}_{8}{ }^{+}$, and $\mathrm{C}_{6} \mathrm{H}_{12}{ }^{+}$molecules. High-mass resolution negative spectra were calibrated using the masses of $\mathrm{C}_{2}^{-}, \mathrm{C}_{3}^{-}, \mathrm{C}_{4}^{-}, \mathrm{C}_{5}^{-}$, and $\mathrm{C}_{6}{ }^{-}$molecules. The relative ion concentration was measured in three different locations for each sample and was normalised to the total ion count. The data processing and evaluation were conducted using the SurfaceLab 6 software package (IONTOF GmbH, Germany).

Scanning electron microscopy coupled with energy-dispersive spectroscopy (SEM-EDS). The longitudinal root sections were sputter-coated with chromium prior to analysis to make them electrically conductive. The morphology of the exterior and interior surface of the root was determined by SEM analysis. Data were obtained using the following SEMs: FEI Nova Nano SEM 230 and FEI 450 field-emission SEM (FEI, USA), each configured with a Bruker silicon drift detector energy dispersive X-ray spectrometer (EDS) (Bruker, USA). Elemental mapping, provided by EDS, was used to visualize the elemantal distributions in support of the other analytical methods. The spatial resolution of the EDS scans was $\sim 6 \mu \mathrm{m}$.

Scanning transmission electron microscopy coupled with energy-dispersive spectroscopy or electron energy-loss spectroscopy analyses (STEM-EDS/EELS). Fresh roots were washed twice with deionized water and a transverse section of the root $(\sim 3 \mathrm{~mm})$ was cut. Roots were fixed with $2.5 \%(\mathrm{v} / \mathrm{v})$ glutaraldehyde PBS for one hour and then PBS alone was used to exchange the solution. Fixed tissues were washed three times with sodium cacodylate buffer and transverse sections were cut using a razor blade. Plant segments were post-fixed in $1 \%(\mathrm{w} / \mathrm{v})$ osmium tetroxide in a sodium cacodylate buffer. The fixed samples were dehydrated in an increasing ethanol:water series $(30 \%, 50 \%, 70 \%, 80 \%, 90 \%$, and $100 \% \mathrm{v} / \mathrm{v})$ and embedded in Spurr's resin. During fixation, dehydration, and infiltration, Biowave microwave (Pelco, Redding, CA, USA) was used to speed up the rate of diffusion. Ultrathin sections of the root $(\sim 60 \mathrm{~nm})$ were cut with a $45^{\circ}$ diamond knife (Diatome, Biel, Switzerland) using an ultramicrotome (Leica EM UC6, Germany). Ultrathin sections were mounted on a lacey carbon support film on a 200 mesh copper support grid and stained with uranyl acetate (2\%) and lead citrate.

STEM-EDS/EELS analysis was carried out using a ARM200F aberration-corrected STEM (JEOL, Japan) to investigate the ultrastructure of the root specimens. Stained specimens were imaged using bright-field modes at a $200 \mathrm{kV}$ accelerating voltage in a scanning mode using a $8 \mathrm{C}(30 \mathrm{pA})$ probe and a $40 \mu \mathrm{m}$ condenser aperture. The composition and speciation of compounds at sub-micron scale in the root were also determined. Compositional spectra at the regions of interest were analyzed by a NORAN System Seven X-ray Microanalysis System (Thermo Fisher, USA) coupled with a large area (1 sr) JEOL EDS detector. EEL spectra were recorded using a GIF model 963 Quantum Energy Filter (Gatan, USA) for determination of the oxidation state. Characterization of iron oxide nanoparticles in roots can be difficult using EELS, as many of the species are damaged or volatilized by the high-energy electron beam and the resin is readily damaged by the very high local electron intensity in the STEM probe. In addition, hydrocarbons on the specimen surface can diffuse to the beam location. Here they are cracked and carbonaceous deposits build-up, obscuring the details under study. To reduce these effects, STEM specimens were cooled to liquid nitrogen temperature using an in situ cooling sample holder prior to examination $^{54}$.

Atomic force microscopy (AFM). The section $(\sim 400 \mathrm{~nm})$ of resin-embedded root was cut using an ultramicrotome and a diamond knife. The surface topography and the distribution of the surface potential across a transverse section of root was determined using AFM (Dimension ICON, Bruker, USA). Tapping mode combined with lift mode was used to measure the surface topography and potential simultaneously (Kelvin probe force microscopy, KPFM). Firstly, the root section was placed onto a polished silicon wafer, the wafer was prefixed to an aluminium holder using silver paint. The sample was then placed and fixed onto the AFM stage. A cobalt-chromium coated AFM probe (SCM-PIT-V2, Bruker AFM probes) was installed onto the scanner head and used for all KPFM measurements. The probe was aligned and tuned near its resonance frequency with a slight offset. The lift height was kept to approximately $100 \mathrm{~nm}$ to avoid any topography artefacts. The scan area was set to $10 \times 10 \mu \mathrm{m}$ with a scan rate of around $0.6 \mathrm{~Hz}$. The applied AC bias (drive 2 amplitude) on the lift pass was set to $500 \mathrm{mV}$. Other parameters, such as setpoint, feedback gain and lock-in phase angle were optimized accordingly.

Received: 8 September 2020; Accepted: 16 December 2020

Published online: 08 January 2021

\section{References}

1. Normile, D. Reinventing rice to feed the world. Science 321, 330-333 (2008).

2. Marschner, P. Marschner's Mineral Nutrition of Higher Plants (Academic Press, London, 2012).

3. Vigani, G., Tarantino, D. \& Murgia, I. Mitochondrial ferritin is a functional iron-storage protein in cucumber (Cucumis sativus) roots. Front. Plant Sci. 4, 316 (2013).

4. Violante, A., Barberis, E., Pigna, M. \& Boero, V. Factors affecting the formation, nature, and properties of iron precipitation products at the soil-root interface. J. Plant Nutr. 26, 1889-1908 (2003). 
5. Pradhan, S. K. et al. Genetic regulation of homeostasis, uptake, bio-fortification and efficiency enhancement of iron in rice. Environ. Exp. Bot. 177, 104066 (2020).

6. Kilcoyne, S. H., Bentley, P. M., Thongbai, P., Gordon, D. C. \& Goodman, B. A. The application of 57Fe Mössbauer spectroscopy in the investigation of iron uptake and translocation in plants. Nucl. Instrum. Meth B 160, 157-166 (2000).

7. Zhang, A. et al. Effect of biochar amendment on yield and methane and nitrous oxide emissions from a rice paddy from Tai Lake plain, China. Agric. Ecosyst. Environ. 139, 469-475 (2010).

8. Huang, M., Yang, L., Qin, H., Jiang, L. \& Zou, Y. Quantifying the effect of biochar amendment on soil quality and crop productivity in Chinese rice paddies. Field Crops Res. 154, 172-177 (2013).

9. Zhang, A. et al. Effects of biochar amendment on soil quality, crop yield and greenhouse gas emission in a Chinese rice paddy: A field study of 2 consecutive rice growing cycles. Field Crops Res. 127, 153-160 (2012).

10. Kim, S. \& Dale, B. E. Global potential bioethanol production from wasted crops and crop residues. Biomass Bioenerg. 26, 361-375 (2004).

11. Wang, Y., Xiao, X., Xu, Y. \& Chen, B. Environmental effects of silicon within Biochar (Sichar) and carbon-silicon coupling mechanisms: A critical review. Environ. Sci. Technol. 53, 13570-13582 (2019).

12. Chan, K. Y., Van Zwieten, L., Meszaros, I., Downie, A. \& Joseph, S. Agronomic values of greenwaste biochar as a soil amendment. Soil Res. 45, 629 (2007).

13. Van Zwieten, L. et al. Effects of biochar from slow pyrolysis of papermill waste on agronomic performance and soil fertility. Plant Soil 327, 235-246 (2009).

14. Joseph, S. et al. Shifting paradigms: Development of high-efficiency biochar fertilizers based on nano-structures and soluble components. Carbon Manag. 4, 323-343 (2013).

15. Chew, J. et al. Biochar-based fertilizer: Supercharging root membrane potential and biomass yield of rice. Sci. Total Environ. 713, $136431(2020)$.

16. Irshad, M. K. et al. Goethite-modified biochar ameliorates the growth of rice (Oryza sativa L.) plants by suppressing Cd and Asinduced oxidative stress in Cd and As co-contaminated paddy soil. Sci. Total Environ. 717, 137086 (2020).

17. Zhang, J.-Y. et al. Effects of nano- $\mathrm{Fe}_{3} \mathrm{O}_{4}$-modified biochar on iron plaque formation and $\mathrm{Cd}$ accumulation in rice (Oryza sativa L.). Environ. Pollut. 260, 113970 (2020).

18. Chen, Z. et al. Mitigation of Cd accumulation in paddy rice (Oryza sativa L.) by Fe fertilization. Environ. Pollut. 231, 549-559 (2017).

19. Küpper, H., Zhao, F. J. \& McGrath, S. P. Cellular compartmentation of zinc in leaves of the hyperaccumulator Thlaspi caerulescens. Plant Physiol. 119, 305-312 (1999).

20. Blackwell, P. et al. Influences of biochar and biochar-mineral complex on mycorrhizal colonisation and nutrition of wheat and sorghum. Pedosphere 25, 686-695 (2015).

21. Rodriguez, N., Menendez, N., Tornero, J., Amils, R. \& de la Fuente, V. Internal iron biomineralization in Imperata cylindrica, a perennial grass: Chemical composition, speciation and plant localization. New Phytol. 165, 781-789 (2005).

22. Neumann, D., Nieden, U. Z., Lichtenberger, O. \& Leopold, I. How does Armeria maritima tolerate high heavy metal concentrations?. J. Plant Physiol. 146, 704-717 (1995).

23. Liu, D. H., Adler, K. \& Stephan, U. W. Iron-containing particles accumulate in organelles and vacuoles of leaf and root cells in the nicotianamine-free tomato mutantchloronerva. Protoplasma 201, 213-220 (1998).

24. Alkhatib, R., Alkhatib, B., Abdo, N., Al-Eitan, L. \& Creamer, R. Physio-biochemical and ultrastructural impact of $\left(\mathrm{Fe}_{3} \mathrm{O}_{4}\right)$ nanoparticles on tobacco. BMC Plant Biol. 19, 253 (2019).

25. Fuente, V. et al. Formation of biomineral iron oxides compounds in a Fe hyperaccumulator plant: Imperata cylindrica (L.) P. Beauv. J. Struct. Biol. 193, 23-32 (2016).

26. Graham, U. M. et al. Tissue specific fate of nanomaterials by advanced analytical imaging techniques-A review. Chem. Res. Toxicol. 33, 1145-1162 (2020).

27. Aoki, D. et al. Distribution of coniferin in freeze-fixed stem of Ginkgo biloba L. by cryo-TOF-SIMS/SEM. Sci. Rep. 6, 31525 (2016).

28. Martin, R. R. et al. Time of flight secondary ion mass spectrometry studies of the distribution of metals between the soil, rhizosphere and roots of Populus tremuloides Minchx growing in forest soil. Chemosphere 54, 1121-1125 (2004).

29. Saito, K. et al. Aluminum localization in the cell walls of the mature xylem of maple tree detected by elemental imaging using time-of-flight secondary ion mass spectrometry (TOF-SIMS). Holzforschung 68, 85-92 (2014).

30. Hanć, A., Piechalak, A., Tomaszewska, B. \& Barałkiewicz, D. Laser ablation inductively coupled plasma mass spectrometry in quantitative analysis and imaging of plant's thin sections. Int. J. Mass spectrom. 363, 16-22 (2014).

31. Shi, J., Gras, M. A. \& Silk, W. K. Laser ablation ICP-MS reveals patterns of copper differing from zinc in growth zones of cucumber roots. Planta 229, 945-954 (2009).

32. Guizani, C., Haddad, K., Limousy, L. \& Jeguirim, M. New insights on the structural evolution of biomass char upon pyrolysis as revealed by the Raman spectroscopy and elemental analysis. Carbon 119, 519-521 (2017).

33. Joseph, S. et al. An investigation into the reactions of biochar in soil. Soil Res. 48, 501-515 (2010).

34. Prendergast-Miller, M. T., Duvall, M. \& Sohi, S. P. Biochar-root interactions are mediated by biochar nutrient content and impacts on soil nutrient availability. Eur. J. Soil Sci. 65, 173-185 (2014).

35. Nielsen, S. et al. Comparative analysis of the microbial communities in agricultural soil amended with enhanced biochars or traditional fertilisers. Agric. Ecosyst. Environ. 191, 73-82 (2014).

36. Hansel, C. M., Fendorf, S., Sutton, S. \& Newville, M. Characterization of Fe plaque and associated metals on the roots of minewaste impacted aquatic plants. Environ. Sci. Technol. 35, 3863-3868 (2001).

37. Gloter, A., Zbinden, M., Guyot, F., Gaill, F. \& Colliex, C. TEM-EELS study of natural ferrihydrite from geological-biological interactions in hydrothermal systems. Earth Planet. Sci. Lett. 222, 947-957 (2004).

38. Rajendran, M. et al. Effect of sulfur and sulfur-iron modified biochar on cadmium availability and transfer in the soil-rice system. Chemosphere 222, 314-322 (2019).

39. Wu, C. et al. The effect of silicon on iron plaque formation and arsenic accumulation in rice genotypes with different radial oxygen loss (ROL). Environ. Pollut. 212, 27-33 (2016).

40. Linke, R., Schreiner, M., Demortier, G. \& Alram, M. Determination of the provenance of medieval silver coins: potential and limitations of X-ray analysis using photons, electrons or protons. X-ray Spectrom. 32, 373-380 (2003).

41. Haynes, R. J. A contemporary overview of silicon availability in agricultural soils. J. Plant Nutr. Soil Sci. 177, 831-844 (2014).

42. Kostic, L. et al. Liming of anthropogenically acidified soil promotes phosphorus acquisition in the rhizosphere of wheat. Biol. Fertility Soils 51, 289-298 (2014).

43. Acosta-Martinez, V. \& Tabatabai, M. Enzyme activities in a limed agricultural soil. Biol. Fertility Soils 31, 85-91 (2000).

44. Chan, K., Van Zwieten, L., Meszaros, I., Downie, A. \& Joseph, S. Using poultry litter biochars as soil amendments. Soil Res. 46, 437-444 (2008).

45. Khan, N. et al. Root iron plaque on wetland plants as a dynamic pool of nutrients and contaminants. Adv. Agron. 138, 1-96 (2016).

46. Kuzyakov, Y. \& Blagodatskaya, E. Microbial hotspots and hot moments in soil: Concept and review. Soil Biol. Biochem. 83, 184-199 (2015).

47. Ma, J., Cai, H., He, C., Zhang, W. \& Wang, L. A hemicellulose-bound form of silicon inhibits cadmium ion uptake in rice (Oryza sativa) cells. New Phytol. 206, 1063-1074 (2015). 
48. Wang, Y., Stass, A. \& Horst, W. J. Apoplastic binding of aluminum is involved in silicon-induced amelioration of aluminum toxicity in maize. Plant Physiol. 136, 3762-3770 (2004).

49. Wang, P., Lombi, E., Zhao, F.-J. \& Kopittke, P. M. Nanotechnology: A new opportunity in plant sciences. Trends Plant Sci. 21, 699-712 (2016).

50. Garvie, L. A. \& Buseck, P. R. Ratios of ferrous to ferric iron from nanometre-sized areas in minerals. Nature 396, 667-670 (1998).

51. Goya, G. F., Berquó, T. S., Fonseca, F. C. \& Morales, M. P. Static and dynamic magnetic properties of spherical magnetite nanoparticles. J. Appl. Phys. 94, 3520-3528 (2003).

52. Yao, C. et al. Developing more effective enhanced biochar fertilisers for improvement of pepper yield and quality. Pedosphere 25, 703-712 (2015).

53. Rawal, A. et al. Mineral-biochar composites: Molecular structure and porosity. Environ. Sci. Technol. 50, 7706-7714 (2016).

54. Mitchell, D. R. Contamination mitigation strategies for scanning transmission electron microscopy. Micron 73, 36-46 (2015).

\section{Acknowledgements}

This study was supported by funds provided by UNSW. This research used the JEOL JEM-ARM200F funded by the Australian Research Council (ARC) - Linkage, Infrastructure, Equipment and Facilities (LIEF) grant (LE120100104) located at the UOW Electron Microscopy Centre and LE140100032 for the ToF-SIMS located at the Mark Wainwright Analytical Centre. The authors acknowledge the support of the Mark Wainwright Analytical Centre at UNSW.

\section{Author contributions}

All authors were involved in designing and performing the research. In particular, X.F., J.C., G.P., L.L. and R.B. conceived the experiments and were in charge of the preparation of the plant root samples. J.H. and M.M. participated in VSM analysis. A.R. performed Raman spectroscopy measurements. R.A. carried out LA-ICP-MS measurements. S.C. took part in ToF-SIMS analsyis. Y.Y. conducted AFM analysis. D.M. performed STEM-EDS/ EELS experiments. S.T. participated in SEM-EDS observations. G.C., C.M., D.M., P.M. and S.J. were involved in writing the manuscript. All authors have given approval to the final version of the manuscript.

\section{Competing interests}

The authors declare no competing interests.

\section{Additional information}

Supplementary Information The online version contains supplementary material available at https://doi. org/10.1038/s41598-020-80377-z.

Correspondence and requests for materials should be addressed to G.C. or S.J.

Reprints and permissions information is available at www.nature.com/reprints.

Publisher's note Springer Nature remains neutral with regard to jurisdictional claims in published maps and institutional affiliations.

(c) (i) Open Access This article is licensed under a Creative Commons Attribution 4.0 International License, which permits use, sharing, adaptation, distribution and reproduction in any medium or format, as long as you give appropriate credit to the original author(s) and the source, provide a link to the Creative Commons licence, and indicate if changes were made. The images or other third party material in this article are included in the article's Creative Commons licence, unless indicated otherwise in a credit line to the material. If material is not included in the article's Creative Commons licence and your intended use is not permitted by statutory regulation or exceeds the permitted use, you will need to obtain permission directly from the copyright holder. To view a copy of this licence, visit http://creativecommons.org/licenses/by/4.0/.

(C) The Author(s) 2021 